Print ISSN: 2093-9582, Online ISSN 2508-4593

http://dx.doi.org/10.21871/KJFM.2020.3.11.1.7

\title{
The Impact of Food Service Franchisee's Customer-oriented Activities on Hedonic, and Utilitarian Values and Loyalty
}

\author{
Hae-Jin JANG*, Sung-Keun WOO**, Yong-Ki LEE*** \\ Received: November 20, 2019 Revised: December 02, 2020 Accepted: December 05, 2020.
}

\begin{abstract}
Purpose - As the competition in the foodservice franchise industry and the market becomes fierce and the entry barrier is lowered, the foodservice franchisor and franchisees strive to increase their competitive advantage in the market. Therefore, the franchisor and franchisees use experience management strategies to enhance the positive experiences of customers visiting the stores. In this regard, this study examines the effects of customer-oriented activities (physical-, social-, health-, and service-oriented activities) on utilitarian and hedonic values, and loyalty using stimulus-organism-response (S-O-R) model and value-expectancy theory. Research design, data, methodology - The data were collected from panels of online survey company, who visited a foodservice franchisee within last month. The survey was conducted for about 15 days from March 7, 2019 to March 21, 2019, and about 3,500 e-mails and messages were distributed to ask for the survey. A total 412 responded and completed the questionnaires. Of the 412 completed questionaires, 12 were discarded due to missing and misinformation data and 400 were retained for further data analysis. Results --The results showed that social oriented activities, health oriented activities, and service oriented activities had positive effects on hedonic value, while physical oriented activities did not have a significant effect on hedonic value. Health oriented activities and service oriented activities had positive effects on utilitarian value, while physical oriented activities and social oriented activities had no significant effects on utilitarian value. Hedonic and utilitarian values also have a positive effect on loyalty. Conclusions - First, food service franchises should provide services and menus in consideration of the health of customers. When a customer visits the store, franchisee should provide more health-oriented food or materials and clean and comfortable conditions so as not to threaten the health of the customer. Second, the food service franchise must build a service-oriented system. Foodservice franchisor need to provide continuous service training not only to the franchisees, but also to the employees of the franchisees. Third, franchise should design a store where customers can form social exchanges through providing various information exchange to customers and making the store as a local community center
\end{abstract}

Keywords: Franchise, Foodservice, Customer-oriented activities, Value, Loyalty.

JEL Classifications: M3, M21, M86.

\section{1. 서론}

외식프랜차이즈 산업과 시장에서의 경쟁이 치열해지고, 진입장벽이 낮아짐에 따라 외식프랜차이즈 본부와 가맹점들은 시장에서의 경쟁적

*First Author's Affiliation: Doctoral Candidate, School of Business, Sejong University, Seoul, Korea, Email: jhj7014@hanmail.net ${ }^{* *}$ Second Author's Affiliation: Professor, Department of Casino Management, Saekyoung University, Gangwon-Do, Korea, Email:Wskosh@hanmail.net

${ }^{* * *}$ Corresponding Author's Affiliation: Professor, School of Business, Sejong University, Seoul, Korea, Email: yongki2@sejong.ac.kr (๑) Copyright: Korean Distribution Science Association (KODISA)

This is an Open Access article distributed under the terms of the Creative Commons Attribution NonCommercial License (https:///creativecommons.org/licenses/by-nc/4.0/) which permits unrestricted non-
우위를 높이기 위한 노력을 하고 있다. 따라서 외식프랜차이즈 본부와 가맹점들은 점포를 방문하는 고객들이 점포 내에서 긍정적 경험을 높이기 위해 경험관리 전략을 이용하고 있다. 그 이유는 고객이 경험한 가치가 고객의 만족, 태도와 충성도에 영향을 미치며(Lee, Ahn, \& Lee, 2019; Lee, Lee, \& Lee, 2019), 그 결과 경영성과를 증가시키기 때문이다(Jani \& Han, 2014). 이것은 외식프랜차이즈 사업이 성공하려면 모든 자원이 고객 중심으로 투자되어야 한다는 것을 의미한다(Athanassopoulos, 2000). 그러나 가맹점은 가맹본부의 지휘에 따라 사업을 영위하기 때문에 자체적인 변화나 시스템을 구축하기 어렵다. 따라서 가맹본부가 고객 중심으로 변화되어 가맹점을 관리해야 성공 가능성이 높아질 수 있다. 고객 지향적 활동은 외식프랜차이즈 기업이 마케팅 전략을 설계하고 
실행하는데 필요한 정보를 획득하여 서비스에 적용시킴으로써 고객에게 보다 긍정적인 가치를 제공할 수 있다.

이런 관점에서, 외식산업에서 기업이 고객에게 어떻게 음식 경험을 제공하는지에 대해 연구의 관심이 증가하고 있다(Davis \& Vollmann, 1990, Jensen \& Hansen, 2007). 소비자가 제품 및 서비스에 만족하면 다시 구매할 가능성이 높아져 기업의 성과가 높아지기 때문이다(Gupta, Mdaughlin, \& Gomez, 2007; Heskett, Jones, Loveman, Sasser, \& Schlesinger, 2004). 외식산업을 대상으로 한 연구에 따르면, 메뉴 품질, 매장 분위기, 좌석, 주문 방법 및 효율성이 기업의 성과에 중요한 것으로 나타났다(Sulek \& Hensley, 2004). 또한 서비스 품질, 직원 대응, 메뉴 가격 및 편의성 식사 경험에 대한 고객의 반응에 직접적인 영향을 미치는 것으로 제시되었다(Robson, 1999; Sulek \& Hensley, 2004).

고객의 서비스 경험에 대한 연구에서 서비스 경험과 만족 사이의 관계에 대한 연구는 다양하게 이루어지고 있다(Shieh \& Cheng, 2007). 특히, 외식업에서도 고객의 서비스 경험과 지각된 가치가 중요하게 다루어지고 있다(Andersson \& Mossberg, 2004). 또한, 일부 연구에서 외식업의 서비스 경험에 대한 우수성, 조화, 정서적 자극, 인정 및 서비스 환경의 지각된 가치를 측정하였다(Jensen \& Hansen, 2007).

고객의 서비스 경험은 인지적과 감정적 측면에서 실용적과 쾌락적 가치로 설명될 수 있다(Batra \& Ahtola, 1990; Holbrook \& Hirschman, 1982). 실용적 가치는 기능적, 경제적인 요소이지만, 쾌락적 가치는 사회적, 정서적, 비경제적 요소가 포함된다. 외식프랜차이즈 기업은 고객에게 쾌락적 및 실용적 가치를 제공한다.

따라서 본 연구는 외식프랜차이즈 기업 또는 가맹점이 고객의 실용적과 쾌락적 가치를 높이기 위한 고객지향적 활동이 무엇인가를 Stimuli-Organism-Response(S-O-R) 모델(Mehrabian \& Russell, 1974)을 적용한 모델을 이용하여 제시하고, 충성도와의 관계를 분석하고자 한다. S-O-R 은 환경 자극이 고객의 행동으로 이어지는 정서적 반응이 포함된 유기체에서 반응을 이끌어내는데 사용될 수 있으며, 본 모형에서 고객지향적 활동은 환경 자극으로 작용한다. 가치 기대 이론은 특정 행동 과정을 취할 것인지 결정할 때 고려할 수 있는 문제를 체계적으로 평가하기 위한 프레임 워크를 제공하며(Palmgreen, Wenner, \& Rosengren, 1985), 사람들이 특정 행동 수행에 대한 의사 결정 요소를 정의하고 평가하는 방법을 연구하는데 도움이 될 수 있다. 기대가치이론에 의하면, 외식프랜차이즈 기업 또는 가맹점의 고객지향적 활동은 고객이 점포를 방문할 때, 기대하는 요인이므로 고객이 어떤 고객지향적 활동을 지각하는 가는 점포 내 고객지향적 활동 관리에 대한 전략적 가이드라인을 제공해줄 것이다.

따라서 본 연구에서는 선행연구들을 참조하여 고객 지향적 활동을 물리적 지향적 활동, 사회 지향적 활동, 건강 지향적 활동, 그리고 서비스 지향적 활동으로 제시하고, 쾌락적 가치와 실용적 가치, 충성도에 미치는 영향을 분석하고자 한다. 고객은 서비스 경험에 의해 가치를
판단하기 때문에 기업의 한정된 자원을 집중할 수 있는 외식프랜차이즈 기업의 마케팅 전략을 수립할 수 있는 실무적 함의가 있다.

\section{2. 이론적 배경}

\section{1. 고객 지향적 활동}

경쟁이 심한 시장 환경에서 기업은 고객에게 우수한 품질의 제품과 서비스를 제공하는데 중점을 두고 있기 때문에 마케팅 지향성은 성공적인 비즈니스 전략 수립의 핵심이다(Day \& Wensley, 1988). 마케팅 지향성은 고객 중심이며 소비자 요구에 초점을 맞추어 성과를 창출한다(Homburg, Müller, \& Klamann, 2011).

많은 연구에서 고객 지향적 활동은 단일 차원으로 측정되어 연구되었다(Brady \& Cronin, 2001; Liaw, Chi, \& Chuang, 2010; Han \& Park, 2018). 그러나 고객 지향적 활동을 단일 차원으로 측정하면, 고객 지향적 활동의 다양한 측면을 연구하기 어려울 수 있다. 따라서 본 연구에서는 고객 지향적 활동을 물리적 지향적 활동, 사회 지향적 활동, 건강 지향적 활동, 그리고 서비스 지향적 활동의 네 가지 차원으로 구분하였다.

건강 지향적 활동은 고객이 건강에 주의를 기울이는 경향을 의미한다(lversen \& Kraft, 2006). 건강 지향적 활동을 설명하기 위해 건강 의식이라는 용어가 사용되기도 한다(Dutta-Bergman, 2004). 건강 지향적 활동은 건강 의식, 건강 정보 지향, 건강 지향적 신념 및 건강 활동의 네 가지로 구성된 다차원적 개념이다(Dutta-Bergman, 2004). 건강 지향적 활동이 높은 고객은 건강에 대해 긍정적인 태도를 갖고 건강을 고려한 소비를 하는 고객이다(Kraft \& Goodell, 1993; Moorman \& Matulich, 1993). 즉, 외식프랜차이즈 산업에서 고객의 건강 지향적 활동은 메뉴만 적용되는 것이 아니라 서비스 환경까지 포함된다.

건강 지향적 활동이 높은 고객은 건강 문제에 지속적으로 관여하여 건강을 유지하려고 한다(Dutta-Bergman, 2005). 건강 지향적 활동은 건강 정보, 건강한 음식 섭취 및 건강 증진 행동에 대한 관심이다(DuttaBergman, 2005; Iversen \& Kraft, 2006). 소비자는 식품의 안전에 대한 위험을 인식하고 신뢰를 잃을 때, 식품과 관련된 문제에 관심을 가진다(Fagerli \& Wandel, 1999; Rozin, Fischler, Imada, Sanubin, \& Wrzesniewski, 1999). 건강은 식품 구매 행동에 중요한 결정 요인이다(Wandel \& Bugge, 1997). 고객의 건강 유지 또는 건강 개선은 식품을 구매하는 주된 이유이다(Schifferstein \& Ophuis, 1998).

외식프랜차이즈 환경에서 서비스 제공은 고객과 서비스 제공 기업 간의 교환에서 무형의 요소이다. 외식업의 직원은 고객과의 관계가 높아야 한다. 외식산업에서 서비스 직원은 중요한 역할을 하며 그들의 행동은 고객의 의견에 직접적인 영향을 미친다(Dennis, Deshamais, 
Cushing, Henson \& Costantino, 2001). 서비스 지향적 활동은 훌륭한 서비스를 창출하고 제공하는 서비스 행동을 지원하고 보상하는데 초점을 맞춘 기업의 시스템이 요구된다(Lytle, Hom, \& Mokwa, 1998).

물리적 환경은 레이아웃, 디자인, 장식 및 심미성이 포함된다(Lee \& Jeong, 2012). Bitner(1992)는 서비스스케이프(servicescape)를 사용하여 물리적 환경을 설명하였다. 서비스 환경은 서비스 구매의 지각된 위험을 줄이고 구매 경험을 향상시킬 수 있기 때문에 서비스 마케팅에서 연구되고 있다(Julian \& Ramaseshan, 1994). Bitner(1992)는 서비스 환경을 주변 조건, 공간 또는 기능의 세 가지 차원으로 구분하였다. 주변 조건은 고객의 오감에 영향을 미치는 조건으로 온도, 조명, 소음, 음악 및 향기가 포함되며, 공간은 특정 기능을 달성하기 위해 설계된 서비스 환경의 시설이다. 또한, 기능은 서비스 환경에서 고객의 행동을 지시하는 서비스 환경의 요소이다.

고객은 서비스 관계로부터 다양한 유형의 사회적 혜택을 제공받는다(Gwinner, Gremler, \& Bitner, 1998). 고객의 외식프랜차이즈에 대한 사회 지향적 활동은 우정과 친숙한 인식이 포함된다. 사회 지향적 활동에 대한 고객의 인식은 충성도 태도, 긍정적 구전, 재구매 의도와 긍정적으로 관계가 있다(Gwinner et al, 1998).

\section{2. 지각된 가치}

지각된 가치는 제품 또는 서비스의 구매를 통해 얻는 가치로 정의된다. 예를 들어, Holbrook(1999)은 지각된 가치를 경험에 대한 상대적 평가로 정의하였으며, 이는 가치가 있는 제품 또는 서비스와 고객 간의 거래를 통해 형성된다고 하였다. 이러한 지각된 가치는 고객의 주관적인 평가이다. 지각된 가치는 고객, 문화 및 시간에 따라 다르다(Sanchez, Callanisa, Rodriguez, \& Moliner, 2006). 지각된 가치는 시간, 사람 및 상황에 따라 변할 수 있다(Holbrook, 1994).

외식프랜차이즈 고객도 경험적 가치에 초점을 두고 있다. 또한, 경험적 가치는 고객이 상품 성능과 기능에 대한 정보를 논리적으로 평가함으로써 쇼핑 효율성과 좋은 제품 선택을 나타내는 실용적 가치가 포함된다(Dennis, King, Fiore, \& Kim, 2007). 경험적 가치 인식은 직접 사용 또는 상품이나 서비스에 대한 먼 거리의 감상과 관련된 상호 작용을 기반으로 한다. 이러한 상호 작용은 고객의 선호에 대한 기초를 제공한다(Mathwick, Malhotra, \& Rigdon, 2002).

많은 연구에서 지각된 가치를 다양하게 연구하고 있다(Boksberger \& Melsen, 2011; Ulaga \& Eggert, 2005). 지각된 가치는 고객이 지불한 총 비용을 고객이 지각하는 성과 또는 혜택이라고 할 수 있다(Baker, Grewal, \& Parasuraman, 1994; Zeithaml, 1988). Butz and Goodstein(1996)은 지각된 가치를 고객이 받는 것(혜택, 품질, 가치 및 유용성)과 지불하는 것(가격, 비용 및 희생)의 차이로 정의하였다. 결과적으로 고객은 제품 관련 태도
또는 정서적 유대를 통해 경쟁 제품을 비교한다(Desai \& Mahajan, 1998). 마케팅 연구에서 쾌락적 가치와 실용적 가치로 구분하여 연구되고 있다. 이러한 연구는 다양한 고객 행동과 구매 결정으로 반영된다(Babin, Darden, \& Griffin, 1994; Roy \& Ng, 2012; Voss, Spangenberg, \& Grohmann, 2003).

실용적 가치는 의도된 추구에 대한 결과에 기인 한다(Babin, Darden, \& Griffin, 1994). 실용적 가치는 기능적 또는 성과 지향적이라고 할 수 있다(Babin et al, 1994; Batra \& Ahtola, 1990). 다른 연구에서 지각된 가치는 단순한 기능적 유용성이라고 하였다(Babin \& Attaway, 2000; Voss et al, 2003). 그러나 상품 및 서비스가 여러 이유로 소비되며, 다양한 소비 경험을 완전히 이해하기 위해서는 무형의 감정적 비용과 혜택이 인정되어야 한다(Babin et al, 1994). 즉, 고객의 소비는 쾌락적이고 실용적인 이유로 발생할 수 있다(Hirschman \& Holbrook, 1982). 쾌락적 소비 경험은 정서적 반응으로 설명된다(O'Cury \& Strahilevitz, 2001). Babin et al.(1994)에 따르면 쾌락적 가치는 주관적이고 개인적이며 재미와 즐거움이 포함된다고 하였다. Hirschman and Holbrook(1982)는 소비자를 문제 해결뿐만 아니라 재미, 환상, 흥분, 감각 자극 및 즐거움을 찾는 사람들이라고 하였다. 외식서비스는 쾌락적과 실용적 서비스 모두를 제공해야 된다. 이러한 경험적 가치는 외식 선택의 동기가 부여된다.

\section{3. 충성도}

충성도는 고객이 제품 또는 서비스를 지속적으로 구매하려는 여부를 말한다(Zeithaml, Bery, \& Parasuraman, 1996). 충성도는 가격 및 품질에 대한 고객의 믿음을 의미하는 첫 번째 단계이다Evanschitkky \& Wunderlich, 2006). 고객이 제품에 대해 긍정적인 신념이나 좋은 인식을 가질 때 자신의 신념에 따라 해당 제품 또는 서비스를 선호하는 경향이 있다. 제품 또는 서비스를 좋아하고 싫어하는 정서적 충성도는 정서적 충성도가 제품 속성이 아니라 제품에 대한 긍정적인 성향을 반영한다(Evanschitzky \& Wunderlich, 2006). 행동적 구성 요소는 인지적 요소 또는 정서적 요소에 의해 결정된 고객의 재구매 의도를 나타낸다(Back, 2005).

\section{3. 연구설계}

\section{1. 연구가설}

본 연구는 외식프랜차이즈의 고객 지향적 활동이 쾌락적 가치와 실용적 가치에 영향을 미치고, 쾌락적 가치와 실용적 가치가 충성도에 
미치는 영향을 검증하기 위해 선행연구를 바탕으로 다음과 같은 연구 가설을 설정하였다.

\subsection{1 외식프랜차이즈의 고객 지향적 활동이 지각된 가치에 미치는 영향}

외식에서 경험은 쾌락적 가치와 실용적 가치를 창출할 수 있다 $\mathrm{Ha} \&$ Jang, 2013). 이러한 외식 경험은 쾌락적 가치와 실용적 가치에 영향을 미칠 수 있다. 그러나 서비스는 무형성이기 때문에 평가하기 어렵다Reimer \& Kuehn, 2005). 따라서 서비스가 제공되는 장소(예: 서비스 환경)는 고객이 긍정적으로 경험을 평가하는데 중요한 영향을 미치는 요인이다Lee, Yoon, \& Lee, 2017). 또한, 서비스는 직원과 고객 간의 상호작용을 통해 사회적 관계가 형성된다Mehrabian \& Russell, 1974). 이러한 이유로 많은 연구에서 물리적 환경, 서비스 품질, 사회적 관계가 포함된 서비스스케이프가 실용적 가치와 쾌락적 가치에 영향을 미치는 것으로 연구되고 있대Chang, Bums, \& Francis, 2004; Dedeoglu, Bilgihan, Ye, Buonincontri, \& Okumus, 2018; Fortin, Undes, Olsen, \& Skallerud, 2011). Jeong \& Jang(2015)은 건강 메뉴가 고객의 쾌락적 가치와 실용적 가치에 영향을 미친다고 하였다. 이와 같은 선행연구를 바탕으로 다음과 같이 외식프랜차이즈의 고객 지향적 활동이 쾌락적 가치와 실용적 가치에 미치는 가설을 설정하였다.

H1: 외식프랜차이즈의 고객 지향적 활동은 쾌락적 가치에 정(+)의 영향을 미칠 것이다.

H1-1: 물리적 지향적 활동은 쾌락적 가치에 정(+)의 영향을 미칠 것이다.

H1-2: 사회적 지향적 활동은 쾌락적 가치에 정(+)의 영향을 미칠 것이다.

H1-3: 건강 지향적 활동은 쾌락적 가치에 정(+)의 영향을 미칠 것이다.

H1-4: 서비스 지향적 활동은 쾌락적 가치에 정(+)의 영향을 미칠 것이다.

H2: 외식프랜차이즈의 고객 지향적 활동은 실용적 가치에 정(+)의 영향을 미칠 것이다.

H2-1: 물리적 지향적 활동은 실용적 가치에 정(+)의 영향을 미칠 것이다.

H2-2: 사회적 지향적 활동은 실용적 가치에 정(+)의 영향을 미칠 것이다.

H2-3: 건강 지향적 활동은 실용적 가치에 정( + )의 영향을 미칠 것이다. H2-4: 서비스 지향적 활동은 실용적 가치에 정(+)의 영향을 미칠 것이다.

\subsection{2 지각된 가치가 충성도에 미치는 영향}

일반적으로 쾌락적 가치와 실용적 가치는 충성도에 영향을 미치는 요인으로 연구되고 있대(Overby \& Lee, 2006; Yoo \& Park, 2016). Ryu, Han, and Jang(2010)은 외식 산업에서 쾌락적 가치보다 실용적 가치가 행동 의도에 더 큰 영향을 미친다고 하였다. 그러나 고객의 소비 경험에 대한 즐거움은 행동 의도를 설명하는 중요한 요인이다Shang, Chen, \& Shen, 2005). 이와 같은 선행연구를 바탕으로 다음과 같이 외식프랜차이즈에 대한 고객의 지각된 쾌락적 가치와 실용적 가치가 충성도에 미치는 가설을 설정하였다.

H3: 쾌락적 가치는 충성도에 정(+)의 영향을 미칠 것이다.

H4: 실용적 가치는 충성도에 정(+)의 영향을 미칠 것이다.

\section{2. 표본설계}

본 연구의 설문은 선행연구를 바탕으로 작성 되었으며, 설문조사 전문 기관을 통해 데이터가 수집되었다. 설문은 최근 1 개월 이내에 외식프랜차이즈 매장 방문 경험이 있는 온라인 설문조사 전문 기관의 패널을 대상으로 조사되었다. 설문조사는 2019 년 3 월 7 일부터 3 월 21 일까지 약 15 일 간 조사되었으며, 약 3,500 명에게 설문조사를 부탁하는 메일 및 메시지가 발송되어 412 명이 설문을 작성하였다. 412 개의 설문 중 불성실한 설문 12 개를 제외한 400 개가 분석에 이용되었다.

\section{3. 변수의 측정 및 정의}

본 연구의 가설 검증을 위해 사용된 변수는 7 점 리커트 척도가 이용되었으며, 표본의 일반적 특성은 명목척도가 이용되었다. 물리적 지향적 활동과 서비스 지향적 활동은 Ryu, Lee, and Kim(2012)의 연구를 본 연구의 상황에 맞게 수정하여 각각 4 개 항목으로 측정되었다. 물리적 지향적 활동은 고객의 요구에 맞게 설계된 외식프랜차이즈 기업의 인테리어 및 익스테리어로 정의되었으며, 서비스 지향적 활동은 고객의 요구에 적합한 서비스 품질로 정의되었다. 사회 지향적 활동은 Kim and Lee(2012)의 연구를 본 연구의 상황에 맞게 수정하여 6 개 항목으로 측정되었으며, 외식프랜차이즈 기업이 지역 사회의 구성원으로 인정받는 정도로 정의되었다. 건강 지향적 활동은 Lee and Lee(2016)의 연구를 본 연구의 상황에 맞게 수정하여 4 개 항목으로 측정되었으며, 외식프랜차이즈 기업이 고객의 건강을 고려하는 정도로 정의되었다. 지각된 가치는 Lee, Kim, Lee, and Kim(2014)의 연구를 본 연구의 상황에 맞게 수정하여 10 개 항목으로 측정되었다. 쾌락적 가치는 외식프랜차이즈 매장의 방문 경험에 대한 정서적 가치로 정의되었으며, 실용적 가치는 외식프랜차이즈 매장의 방문 경험에 대한 
비용 대비 가치로 정의되었다. 충성도는 $\operatorname{Das(2014)ㅇㅢ~ㅇㅕㄴㄱㅜㄹㅡㄹ~ㅂㅗㄴ~ㅇㅕㄴㄱㅜㅇㅢ~}$ 상황에 맞게 수정하여 6 개 항목으로 측정되었으며, 외식프랜차이즈를 지속적으로 방문하고 추천하려는 정도로 정의되었다.

\section{4. 실증분석}

\section{1. 표본의 일반적 특성}

본 연구에 이용된 400 명에 대한 표본의 일반적 특성은 Table: 1 과 같다. 성별은 남자가 208 명(52.0\%)으로 여성 192 명(48.0\%) 보다 많은 것으로 나타났다. 결혼 유무는 기혼이 257 명(64.3\%)으로 미혼 143 명(35.8\%) 보다 많은 것으로 나타났다. 연령대는 50 세 이상이 114 명(28.5\%)으로 가장 많이 나타났으며, 다음으로 40 대가 112 명(28.0\%), 30 대가 89 명(223\%), 그리고 20 대가 85 명(213\%)의 순으로 나타났다.

Table 1: Demographic Profile of the Respondents $(n=400)$

\begin{tabular}{|c|c|c|c|}
\hline & & $\mathbf{n}$ & $\%$ \\
\hline \multirow{2}{*}{ Gender } & Male & 208 & 52.0 \\
\hline & Female & 192 & 48.0 \\
\hline \multirow{2}{*}{ Marital status } & Single & 143 & 35.8 \\
\hline & Married & 257 & 64.3 \\
\hline \multirow{4}{*}{ Age } & $20-29$ & 85 & 21.3 \\
\hline & $30-39$ & 89 & 22.3 \\
\hline & $40-49$ & 112 & 28.0 \\
\hline & $50-59$ & 114 & 28.5 \\
\hline \multirow{4}{*}{$\begin{array}{c}\text { Educational } \\
\text { level }\end{array}$} & Below high school & 76 & 19.0 \\
\hline & Undergraduate & 44 & 11.0 \\
\hline & Four year university & 253 & 63.3 \\
\hline & Graduate school & 27 & 6.8 \\
\hline \multirow{7}{*}{ Job } & Student & 33 & 8.3 \\
\hline & Officer & 186 & 46.5 \\
\hline & Professional & 42 & 10.5 \\
\hline & Sales & 33 & 8.3 \\
\hline & Technical & 16 & 4.0 \\
\hline & Housewife & 68 & 17.0 \\
\hline & Others & 22 & 5.5 \\
\hline \multirow{6}{*}{$\begin{array}{l}\text { Monthly } \\
\text { income }\end{array}$} & Less than 1 million won & 8 & 2.0 \\
\hline & $\begin{array}{l}1 \text { million - Less than } 2 \\
\text { million won }\end{array}$ & 35 & 8.8 \\
\hline & $\begin{array}{l}2 \text { million - Less than } 4 \\
\text { million won }\end{array}$ & 72 & 18.0 \\
\hline & $\begin{array}{l}4 \text { million - Less than } 6 \\
\text { million won }\end{array}$ & 139 & 34.8 \\
\hline & $\begin{array}{c}6 \text { million - Less than } 8 \\
\text { million won }\end{array}$ & 87 & 21.8 \\
\hline & More than 8 million won & 59 & 14.8 \\
\hline
\end{tabular}

학력은 대학교 재학 및 졸업이 253 명(63.3\%)으로 가장 많이 나타났으며, 고등학교 졸업 이하가 76 명(19.0\%), 전문대학교 재학 및 졸업이 44 명(11.0\%), 그리고 대학원 졸업이 27 명(6.8\%)의 순으로 나타났다. 직업은 사무직이 186 명(46.5\%)으로 가장 많이 나타났으며, 가정주부가 68 명(17.0\%), 전문직이 42 명(10.5\%), 학생과 판매 서비스직이 각각 33 명(8.3\%), 기타가 22 명(5.5\%), 그리고 생산 기술직이 16 명(4.0\%)의 순으로 나타났다. 마지막으로 월 평균 소득은 400 만 원 600 만 원 미만이 139 명(34.8\%)으로 가장 많이 나타났으며, 다음으로 600 만 원 800 만 원 미만이 87 명(218\%), 200 만 원 400 만 원 미만이 72 명(18.0\%), 800 만 원 이상이 59 명(14.8\%), 100 만 원 200만 원 미만이 35 명(8.8\%), 그리고 100 만 원 미만이 8 명(2.0\%)의 순으로 나타났다.

\section{2. 측정모형 분석}

본 연구에 사용된 측정 변수들의 집중타당성과 판별타당성을 검증하기 위해 측정모형분석이 실시되었다.

Table 2: Measurement Model ${ }^{\mathrm{a}}$

\begin{tabular}{|c|c|c|c|c|}
\hline Constructs and items & $\begin{array}{c}\text { Standardized } \\
\text { factor loadings }\end{array}$ & $\mathbf{C C R}^{\mathrm{b}}$ & $\mathbf{A V E}^{\mathrm{c}}$ & $\begin{array}{c}\text { Cronbach } \\
\alpha\end{array}$ \\
\hline Physical oriented activities & & 0.877 & 0.721 & 0.885 \\
\hline The exterior is attractive. & - & & & \\
\hline The interior is comfortable. & 0.842 & & & \\
\hline The interior is great. & 0.845 & & & \\
\hline Staff behavior is neat. & 0.861 & & & \\
\hline Social oriented activities & & 0.832 & 0.605 & 0.862 \\
\hline $\begin{array}{l}\text { It is the center of the } \\
\text { community. }\end{array}$ & 0.730 & & & \\
\hline $\begin{array}{l}\text { Local residents use many } \\
\text { stores. }\end{array}$ & - & & & \\
\hline $\begin{array}{c}\text { You can get local } \\
\text { information from the store. }\end{array}$ & - & & & \\
\hline $\begin{array}{l}\text { The exterior of the store } \\
\text { blends well with the local } \\
\text { landscape. }\end{array}$ & 0.782 & & & \\
\hline $\begin{array}{l}\text { The store is suitable as a } \\
\text { meeting place. }\end{array}$ & 0.760 & & & \\
\hline $\begin{array}{l}\text { Stores play a large role in } \\
\text { public spaces in the } \\
\text { community }\end{array}$ & 0.836 & & & \\
\hline Health oriented activities & & 0.843 & 0.662 & 0.892 \\
\hline The air in the store is clean. & 0.863 & & & \\
\hline $\begin{array}{l}\text { The food used organic } \\
\text { ingredients. }\end{array}$ & 0.866 & & & \\
\hline
\end{tabular}




\begin{tabular}{|c|c|c|c|c|}
\hline $\begin{array}{l}\text { The store is equipped with } \\
\text { eco-friendly building } \\
\text { materials and facilities. }\end{array}$ & 0.751 & & & \\
\hline We can rest enough at store. & 0.767 & & & \\
\hline Service oriented activities & & 0.784 & 0.593 & 0.834 \\
\hline $\begin{array}{l}\text { The reservation was } \\
\text { provided correctly. }\end{array}$ & 0.784 & & & \\
\hline $\begin{array}{c}\text { The service was provided } \\
\text { quickly. }\end{array}$ & 0.734 & & & \\
\hline $\begin{array}{c}\text { The staff was happy to help } \\
\text { me. }\end{array}$ & - & & & \\
\hline The staff was excellent. & 0.791 & & & \\
\hline Hedonic value & & 0.887 & 0.687 & 0.896 \\
\hline Gave me pleasure. & 0.824 & & & \\
\hline Made me feel good. & 0.851 & & & \\
\hline $\begin{array}{c}\text { After the visit, the image of } \\
\text { the food service franchise } \\
\text { improved. }\end{array}$ & 0.830 & & & \\
\hline It gave me a boost. & 0.809 & & & \\
\hline It was interesting to me. & - & & & \\
\hline Utilitarian value & & 0.846 & 0.673 & 0.862 \\
\hline \multicolumn{5}{|l|}{$\begin{array}{l}\text { It was relatively } \\
\text { economical. }\end{array}$} \\
\hline $\begin{array}{l}\text { The service level was higher } \\
\text { than the cost paid. }\end{array}$ & 0.818 & & & \\
\hline $\begin{array}{c}\text { Cheaper and better than } \\
\text { other food service franchise. }\end{array}$ & 0.820 & & & \\
\hline $\begin{array}{l}\text { The quality of service is } \\
\text { high overall. }\end{array}$ & 0.823 & & & \\
\hline \multicolumn{5}{|l|}{$\begin{array}{l}\text { I had a good service during } \\
\text { my visit. }\end{array}$} \\
\hline Loyalty & & 0.918 & 0.732 & 0.933 \\
\hline $\begin{array}{l}\text { I want to visit again in the } \\
\text { future. }\end{array}$ & 0.842 & & & \\
\hline I have a good image. & 0.839 & & & \\
\hline $\begin{array}{l}\text { I will recommend it to my } \\
\text { friends or others. }\end{array}$ & 0.853 & & & \\
\hline $\begin{array}{c}\text { I will speak positively to } \\
\text { others. }\end{array}$ & 0.860 & & & \\
\hline $\begin{array}{l}\text { I have come to prefer this } \\
\text { food service franchise. }\end{array}$ & 0.884 & & & \\
\hline
\end{tabular}

${ }^{\mathrm{a}} \chi^{2}=587.430\left(\mathrm{df}=259, \chi^{2} / \mathrm{df}=2.268, \mathrm{p}\right.$-value $\left.=0.000\right), \mathrm{CFI}=0.963$, NFI $=0.936, \mathrm{GFI}=0.899, \mathrm{RMR}=0.038, \mathrm{RMSEA}=0.056$

${ }^{\mathrm{b}} \mathrm{CCR}$ (Composite construct reliability)

${ }^{c}$ AVE(Average variance extracted)

* Items were deleted during confirmatory factor analysis.
분석 결과, Table: 2 와 같이, 적합도 지수는 $\chi^{2}=587.430(\mathrm{df}=259$, $\chi^{2} / \mathrm{df}=2268$, p-value=0.000), CF=0.963, NH=0.936, GH=0.899, RMR=0.038, $\mathrm{RMSEA}=0.056$ 으로 나타나 구조모형 분석에 적합한 것으로 분석되었다. 또한, 집중타당성을 검증하기 위한 요인적재값은 0.6 이상으로 나타났다(Chin, 1998). 또한, 변수들이 요인을 설명하는 정도인 복합신뢰도(CCR)가 0.7 이상으로 나타나 Hair, Black, Babin, Anderson and Tatham(2010)의 요구가 충족되었다. 평균분산 추출 값(AVE)은 0.5 이상으로 나타났으며, 상관계수 값과의 비교를 통해 판별타당성이 검증되었다(Bagozi, \& Yi, 1988). 또한 각 요인의 신뢰도 값(Cronbach $\alpha)$ 은 0.7 이상으로 신뢰도가 확보된 것으로 나타났다(Nunnally, 1978).

\section{3. 상관관계 분석}

확인적 요인분석과 신뢰도 분석 결과, 단일차원성이 검증된 요인들에 대한 상관관계 분석을 통해 상관관계 방향과 상관관계의 크기는 Table: 3 과 같이 나타났다. 연구가설에서 제시한 요인들 간 관계의 방향은 모두 정(+)의 방향으로 유의한 관계로 나타나 향후 분석에 이용되었다.

\section{4. 연구모형의 검증}

본 연구에 이용된 외식프랜차이즈 기업의 고객 지향적 활동, 쾌락적 가치, 실용적 가치, 그리고 충성도로 구성된 전체적 모형을 구조방정식 모형(SEM)으로 검증한 결과, 적합도는 $\chi^{2}=646.171\left(\mathrm{df}=263, \chi^{2} / \mathrm{df}=2.457, \mathrm{p}-\right.$ value $=0.000), \quad \mathrm{GH}=0.891, \quad \mathrm{NFI}=0.930, \quad \mathrm{CH}=0.957, \quad \mathrm{RMR}=0.043$, $\mathrm{RMSEA}=0.060$ 으로 나타났다. 또한, 내생변수가 외생변수에 의해서 설명되는 설명력 $\left(\mathrm{R}^{2}\right)$ 은 쾌락적 가치가 $0.790(79.0 \%)$, 실용적 가치가 $0.811(81.1 \%)$, 그리고 충성도가 $0.815(81.5 \%)$ 로 나타났다.

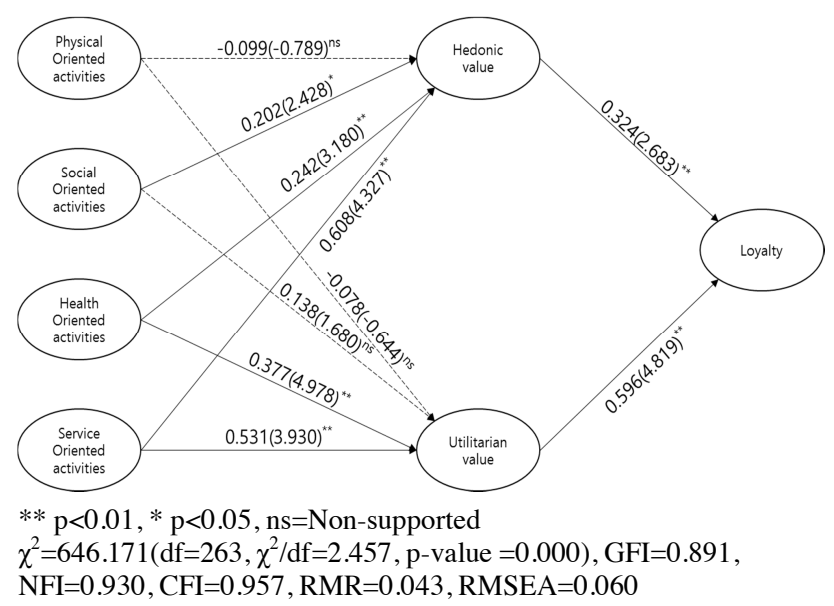

Figure 1: Estimates of the Structural Model 


\section{5. 연구가설의 검증}

본 연구에 이용된 외식프랜차이즈 기업의 고객 지향적 활동이 쾌락적 가치, 실용적 가치, 그리고 충성도에 미치는 영향에 대한 가설을 검증하기 위해 구조모형을 분석한 결과는 Table: 4 와 같다.

Table 3: Construct Intercorrelations, Mean and Standard Deviation

\begin{tabular}{|l|c|c|c|c|c|c|c|}
\hline & $\mathbf{1}$ & $\mathbf{2}$ & $\mathbf{3}$ & $\mathbf{4}$ & $\mathbf{5}$ & $\mathbf{6}$ & $\mathbf{7}$ \\
\hline 1. Physical oriented activities & 1 & & & & & & \\
\hline 2.Social oriented activities & $0.685^{* *}$ & 1 & & & & & \\
\hline 3.Health oriented activities & $0.564^{* *}$ & $0.632^{* *}$ & 1 & & & & \\
\hline 4.Service oriented activities & $0.711^{* *}$ & $0.639^{* *}$ & $0.648^{* *}$ & 1 & & & \\
\hline 5.Hedonic value & $0.661^{* *}$ & $0.663^{* *}$ & $0.705^{* *}$ & $0.740^{* *}$ & 1 & & \\
\hline 6.Utilitarian value & $0.600^{* *}$ & $0.648^{* *}$ & $0.741^{* *}$ & $0.697^{* *}$ & $0.797^{* *}$ & 1 & \\
\hline 7.Loyalty & $0.715^{* *}$ & $0.642^{* *}$ & $0.654^{* *}$ & $0.698^{* *}$ & $0.788^{* *}$ & $0.800^{* *}$ & 1 \\
\hline \multicolumn{1}{c|}{ Mean } & 5.647 & 5.254 & 4.736 & 5.211 & 5.135 & 4.986 & 5.184 \\
\hline SD & 0.942 & 0.936 & 1.043 & 0.944 & 0.925 & 0.941 & 0.982 \\
\hline
\end{tabular}

$* * \mathrm{p}<0.01$

Table 4: Standardized Parameter Estimates

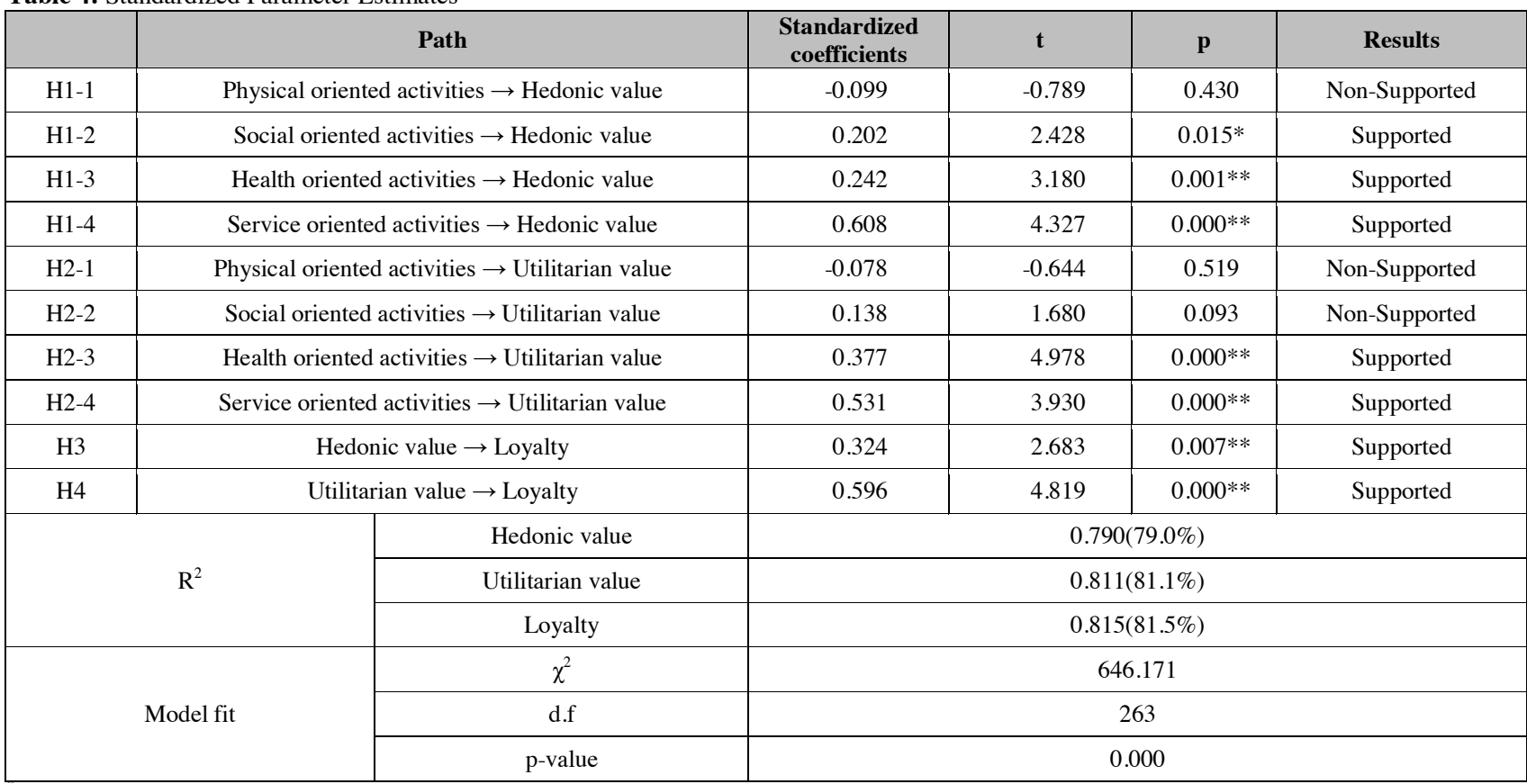

$\mathrm{p}<0.01 ;{ }^{*} \mathrm{p}<0.05$

$\chi^{2}=646.171\left(\mathrm{df}=263, \chi^{2} / \mathrm{df}=2.457, \mathrm{p}-\right.$ value $\left.=0.000\right), \mathrm{GFI}=0.891, \mathrm{NFI}=0.930, \mathrm{CFI}=0.957, \mathrm{RMR}=0.043, \mathrm{RMSEA}=0.060$

$\mathrm{H} 1$ 은 외식프랜차이즈 기업의 고객 지향적 활동이 쾌락적 가치에 미치는 영향을 알아보기 위한 것이다. 먼저, 물리적 지향적 활동이 쾌락적 가치에 정(+)의 영향을 미칠 것이라는 가설 $\mathrm{H1}-1$ 은 경로계수 값이 $-0.099, \mathrm{t}$ 값은 -0.789 로 물리적 지향적 활동은 쾌락적 가치에 유의한 정(+)의 영향을 미치지 않는 것으로 나타났다(p>0.05). 따라서 H1-1 은
기각되었다. 다음으로 사회 지향적 활동이 쾌락적 가치에 정(+)의 영향을 미칠 것이라는 가설 $\mathrm{H1}-2$ 의 경로계수 값은 0.202 , t값은 -0.789 로 사회 지향적 활동은 쾌락적 가치에 유의한 정(+)의 영향을 미치는 것으로 나타났다(p<0.05). 따라서 $\mathrm{H} 1-2$ 는 채택되었다. 건강 지향적 활동이 쾌락적 가치에 정(+)의 영향을 미칠 것이라는 가설 $\mathrm{H1}-3$ 의 
경로계수 값은 $0.242, \mathrm{t}$ 값은 3.180 으로 건강 지향적 활동은 쾌락적 가치에 유의한 정( +$)$ 의 영향을 미치는 것으로 나타났다(p<0.05). 따라서 H1-3 은 채택되었다. 서비스 지향적 활동이 쾌락적 가치에 정(+)의 영향을 미칠 것이라는 가설 $\mathrm{H} 1-4$ 의 경로계수 값은 $0.608, \mathrm{t}$ 값은 4.327 로 서비스 지향적 활동은 쾌락적 가치에 유의한 정(+)의 영향을 미치는 것으로 나타났다(p<0.05). 따라서 H1-4 는 채택되었다. H2 는 외식프랜차이즈 기업의 고객 지향적 활동이 실용적 가치에 미치는 영향을 알아보기 위한 것이다. 먼저, 물리적 지향적 활동이 실용적 가치에 정(+)의 영향을 미칠 것이라는 가설 H2-1 은 경로계수 값이 $0.078, \mathrm{t}$ 값은 -0.644 로 물리적 지향적 활동은 실용적 가치에 유의한 정(+)의 영향을 미치지 않는 것으로 나타났다(p>0.05). 따라서 H2-1 은 기각되었다.

다음으로 사회 지향적 활동이 실용적 가치에 정(+)의 영향을 미칠 것이라는 가설 $\mathrm{H} 2-2$ 의 경로계수 값은 $0138, \mathrm{t}$ 값은 1680 으로 사회 지향적 활동은 실용적 가치에 유의한 정(+)의 영향을 미치지 않는 것으로 나타났다( $p>0.05$. 따라서 $\mathrm{H} 2-2$ 는 기각되었다. 건강 지향적 활동이 실용적 가치에 정(+)의 영향을 미칠 것이라는 가설 $\mathrm{H} 2-3$ 의 경로계수 값은 $0.377, \mathrm{t}$ 값은 4.978 로 건강 지향적 활동은 실용적 가치에 유의한 정( + )의 영향을 미치는 것으로 나타났다( $(\mathrm{p}<0.05)$. 따라서 H2-3은 채택되었다. 서비스 지향적 활동이 실용적 가치에 정(+)의 영향을 미칠 것이라는 가설 H2-4 의 경로계수 값은 $0.531, \mathrm{t}$ 값은 3.930 으로 서비스 지향적 활동은 실용적 가치에 유의한 정(+)의 영향을 미치는 것으로 나타났다(p<0.05). 따라서 $\mathrm{H} 2-4$ 는 채택되었다.

$\mathrm{H} 3$ 과 $\mathrm{H} 4$ 는 지각된 가치가 충성도에 미치는 영향을 알아보기 위한 것이다. 먼저 쾌락적 가치가 충성도에 정(+)의 영향을 미칠 것이라는 $\mathrm{H} 3$ 은 경로계수 값은 $0.324, \mathrm{t}$ 값은 2.683 으로 쾌락적 가치는 충성도에 유의한 정( $(+)$ 의 영향을 미치는 것으로 나타났다(p<0.05). 따라서 H3 은 채택되었다. 다음으로 실용적 가치가 충성도에 정(+)의 영향을 미칠 것이라는 $\mathrm{H} 4$ 는 경로계수 값은 $0.596, \mathrm{t}$ 값은 4.819 로 실용적 가치는 충성도에 유의한 정(+)의 영향을 미치는 것으로 나타났다(p<0.05). 따라서 $\mathrm{H4}$ 는 채택되었다.

\section{5. 결론}

본 연구는 외식프랜차이즈 기업의 고객 지향적 마케팅 전략을 수립하기 위해 물리적 지향적 활동, 건강 지향적 활동, 사회 지향적 활동, 그리고 서비스 지향적 활동으로 구성된 고객 지향적 활동이 쾌락적 가치와 실용적 가치에 미치는 영향을 파악하고 쾌락적 가치와 실용적 가치가 충성도에 미치는 영향을 파악하였다. 분석 결과 사회 지향적 활동, 건강 지향적 활동, 그리고 서비스 지향적 활동은 쾌락적 가치에 정(+)의 영향을 미치는 것으로 나타났으나, 물리적 지향적 활동은
쾌락적 가치에 유의한 영향을 미치지 않는 것으로 나타났다. 건강 지향적 활동과 서비스 지향적 활동은 실용적 가치에 정(+)의 영향을 미치는 것으로 나타났으나, 물리적 지향적 활동과 사회 지향적 활동은 실용적 가치에 유의한 영향을 미치지 않는 것으로 나타났다. 또한, 쾌락적 가치와 실용적 가치는 충성도에 정(+)의 영향을 미치는 것으로 나타났다.

분석 결과에 따는 토의는 다음과 같다.

첫째, 외식프랜차이즈 기업의 고객 지향적 활동은 지각된 가치를 통해 충성도에 영향을 미치는 것으로 나타났다. 이러한 결과는 고객 지향적 활동이 고객을 자극하고 지각된 가치가 유기체를 통해 반응하는 StimuliOrganism-Response(S-O-R) 모델(Mehrabian \& Russel, 1974)이 검증되었다. 또한 이러한 연구는 외식프랜차이즈 고객의 서비스 경험이 인지와 감정이 포함된 지각된 가치에 영향을 미친다고 연구한 Batra and Ahtola(1990)의 연구와 일치하는 것으로 나타났다.

둘째, 사회 지향적 활동, 건강 지향적 활동, 그리고 서비스 지향적 활동은 쾌락적 가치에 긍정적 영향을 미치는 것으로 나타났으나, 물리적 지향적 활동은 유의한 영향을 미치지 않는 것으로 나타났다. 이러한 연구 결과는 서비스 환경을 통해 고객이 긍정적으로 경험을 평가하는데 중요한 영향을 미치는 것으로 연구한 Lee et al.(2017)의 연구와 다른 것으로 나타났다. 이러한 이유는 외식업의 영업 기간이 짧기 때문에 대부분의 매장이 오래되지 않고 깨끗한 환경이기 때문일 수 있다.

셋째, 건강 지향적 활동과 서비스 지향적 활동은 실용적 가치에 긍정적 영향을 미치는 것으로 나타났으나, 물리적 지향적 활동과 사회 지향적 활동은 실용적 가치에 유의한 영향을 미치지 않는 것으로 나타났다. 이러한 분석 결과는 물리적 환경, 서비스 품질, 사회적 관계가 실용적 가치와 쾌락적 가치에 영향을 미친다고 연구한 Chang et al.(2004)의 연구와 일부 다른 것으로 나타났다.

본 연구의 이론적 시사점은 다음과 같다.

먼저, 본 연구는 외식프랜차이즈 고객의 경험과 행동을 설명하기 위하여 환경심리학의 S-O-R 이론을 이용하여 자극을 고객지향적 활동, 유기체를 실용적과 쾌락적 가치, 그리고 반응을 충성도로 제시하였다는 것이다. 특히, 본 연구는 자극 요인에 건강지향적 활동을 포함시켜 최근 고객이 점포를 이용하면서 기대하는 요인을 반영하여, S-O-R 모형을 확장하였다. 둘째, 본 연구는 다차원의 고객지향적 활동들이 고객이 점포 내에서 경험하는 실용적과 쾌락적 가치에 미치는 영향을 분석하여, 고객지향적 활동들이 실용적과 쾌락적 가치에 미치는 상쇄효과(trade-off effect)를 파악할 수 있도록 하였다.

첫째, 외식프랜차이즈 기업은 고객의 건강을 고려한 서비스 및 메뉴를 제공해야 한다. 예를 들어, 식용유를 오래 사용하면 건강에 좋지 않은 물질이 생성되기 때문에 일부 치킨프랜차이즈는 오래된 식용유를 사용하지 않기 위해 브랜드부터 바꾸었다. 또한 이 브랜드는 한 번의 
식용유로 한정된 치킨만 조리할 수 있는지 고객이 확인할 수 있는 어플리케이션까지 만들어 배포하고 있다. 최근 환경 호르몬에 대한 고객의 인식이 증가하여 메뉴 뿐 아니라 실내 환경에 대한 문제도 크게 인식하고 있다. 즉, 고객이 매장에 방문하였을 때, 고객의 건강을 위협하지 않도록 쾌적하고 안전한 매장으로 설계되어야 한다.

둘째, 외식프랜차이즈 기업은 서비스 지향적 시스템을 구축해야 한다. 고객 서비스는 대부분 직원을 통해 제공되기 때문에 외식프랜차이즈 기업은 서비스 매뉴얼을 고객 지향적으로 개발해야 한다. 외식프랜차이즈 기업은 이러한 매뉴얼로 가맹점뿐만 아니라 가맹점의 직원까지 지속적인 서비스 교육을 실시할 필요가 있다.

셋째, 외식프랜차이즈는 고객이 사회적 교류를 형성할 수 있는 매장으로 설계되어야 한다. 예를 들어 일부 커피숍은 처음 고객을 유치할 때, 음료를 구매하지 않더라도 매장에서 쉬거나, 모임을 가질 수 있게 설계되었으나, 최근에는 각 테이블의 전원 플러그를 제거하고 음료를 구매하지 않으면 이용할 수 없게 설계하고 있다. 물론 음료를 구매하지 않고 너무 오랫동안 자리를 차지하고 있으면 다른 고객의 불편을 초래하지만, 대부분의 고객의 초기 인지와 다르기 때문에 인지 불일치가 발생할 수 있다.

한편, 본 연구의 한계점과 향후 연구방향은 다음과 같다.

본 연구는 외식프랜차이즈 기업의 가맹점 방문 고객을 대상으로 연구되었다. 고객이 외식프랜차이즈 본사의 고객 지향적 활동을 직접 경험하기 어렵다. 따라서 고객이 외식프랜차이즈 기업의 고객 지향적 활동을 가맹점을 대상으로 간접 경험할 수밖에 없다. 그러나 외식프랜차이즈 가맹본부와 가맹점은 계약관계에 있는 다른 기업이라고 할 수 있다. 따라서 향후 연구에서는 외식프랜차이즈 본사의 직영점과 가맹점을 구분하여 연구할 필요가 있다. 또한, 본 연구의 외식프랜차이즈는 커피와 음료가 포함된 외식산업 전반에 대해 연구되었다. 그러나 커피와 식사에 대한 고객의 욕구는 다를 것이다. 따라서 향후 연구에서는 업종별로 구분하여 연구할 필요가 있다.

\section{References}

Andersson, T. D. \& Mossberg, L. (2004). The dining experience: Do restaurants satisfy customer needs?. Food Service Technology, 4(4), 171-177.

Athanassopoulos, A. D. (2000). Customer satisfaction cues to support market segmentation and explain switching behavior. Journal of Business Research, 47(3), 191-207.

Babin, B. J., \& Attaway, J. S. (2000). Atmospheric affect as a tool for creating value and gaining share of customer. Journal of Business Research, 49(2), 91-99.

Babin, B. J., Darden, W. R., \& Griffin, M. (1994). Work and/or fun: Measuring hedonic and utilitarian shopping value. Journal of Consumer Research, 20(4), 644-656.

Back, K. J. (2005). The effects of image congruence on customers' brand loyalty in the upper middle-class hotel industry. Journal of Hospitality \& Tourism Research, 29(4), 448-467.

Bagozzi, R. P., \& Yi, Y. (1988). On the evaluation of structural equation models. Journal of the Academy of Marketing Science, 16(1), 74-94.

Baker, J., Grewal, D., \& Parasuraman, A. (1994). The influence of store environment on quality inferences and store image. Journal of the Academy of Marketing Science, 22(4), 328-339.

Batra, R., \& Ahtola, O. T. (1991). Measuring the hedonic and utilitarian sources of consumer attitudes. Marketing Letters, 2(2), 159-170.

Bitner, M. J. (1992). Servicescapes: The impact of physical surroundings on customers and employees. Journal of Marketing, 56(2), 57-71.

Boksberger, P. E., \& Melsen, L. (2011). Perceived value: A critical examination of definitions, concepts and measures for the service industry. Journal of Services Marketing, 25(3), 229-240.

Brady, M. K., \& Cronin Jr, J. J. (2001). Customer orientation: Effects on customer service perceptions and outcome behaviors. Journal of service Research, 3(3), 241-251.

Butz Jr, H. E., \& Goodstein, L. D. (1996). Measuring customer value: Gaining the strategic advantage. Organizational Dynamics, 24(3), 63-77.

Chang, E., Burns, L. D., \& Francis, S. K. (2004). Gender differences in the dimensional structure of apparel shopping satisfaction among Korean consumers: The role of hedonic shopping value. Clothing and Textiles Research Journal, 22(4), 185-199.

Chin, W. W. (1998). Commentary: Issues and opinion on structural equation modeling. MIS Quarterly, 22(1), 7-16.

Das, G. (2014). Linkages of retailer awareness, retailer association, retailer perceived quality and retailer loyalty with purchase intention: A study of Indian food retail brands. Journal of Retailing and Consumer Services, 21(3), 284-292.

Davis, M. M., \& Vollmann, T. E. (1990). A framework for relating waiting time and customer satisfaction in a service operation. Journal of Services Marketing, 4(1), 61-69.

Day, G. S., \& Wensley, R. (1988). Assessing advantage: A framework for diagnosing competitive superiority. Journal of Marketing, 52(2), 1-20.

Dedeoglu, B. B., Bilgihan, A., Ye, B. H., Buonincontri, P., \& Okumus, F. (2018). The impact of servicescape on hedonic value and behavioral intentions: The importance of previous experience. International Journal of Hospitality Management, $72,10-20$.

Dennis, B., Desharnais, R. A., Cushing, J. M., Henson, S. M., \& Costantino, R. F. (2001). Estimating chaos and complex dynamics in an insect population. Ecological Monographs, 71(2), 277-303.

Dennis, C., King, T., Fiore, A. M., \& Kim, J. (2007). An integrative framework capturing experiential and utilitarian shopping experience. International Journal of Retail \& Distribution Management, 35(6), 421-442.

Desai, K. K., \& Mahajan, V. (1998). Strategic role of affect-based attitudes in the acquisition, development, and retention of customers. Journal of Business Research, 42(3), 309-324.

Dutta-Bergman, M. J. (2004). Primary sources of health information: Comparisons in the domain of health attitudes, 
health cognitions, and health behaviors. Health Communication, 16(3), 273-288.

Dutta-Bergman, M. J. (2005). Theory and practice in health communication campaigns: A critical interrogation. Health Communication, 18(2), 103-122.

Eggert, A., Ulaga, W., \& Schultz, F. (2006). Value creation in the relationship life cycle: A quasi-longitudinal analysis. Industrial Marketing Management, 35(1), 20-27.

Evanschitzky, H., \& Wunderlich, M. (2006). An examination of moderator effects in the four-stage loyalty model. Journal of Service Research, 8(4), 330-345.

Fagerli, R. A., \& Wandel, M. (1999). Gender differences in opinions and practices with regard to a healthy diet. Appetite, 32(2), 171-190.

Fortin, D., Uncles, M., Olsen, S. O., \& Skallerud, K. (2011). Retail attributes' differential effects on utilitarian versus hedonic shopping value. Journal of Consumer Marketing, 28(7), 532-539.

Gupta, S., McLaughlin, E., \& Gomez, M. (2007). Guest satisfaction and restaurant performance. Cornell Hotel and Restaurant Administration Quarterly, 48(3), 284-298.

Gwinner, K. P., Gremler, D. D., \& Bitner, M. J. (1998). Relational benefits in services industries: The customer's perspective. Journal of the Academy of Marketing Science, 26(2), 101-114.

Ha, J., \& Jang, S. S. (2013). Attributes, consequences, and consumer values. International Journal of Contemporary Hospitality Management, 25(3), 383-409.

Hair Jr, J. F., Black, W. C., Babin, B. J., Anderson, R. E., \& Tatham, R. L. (2010). SEM: An introduction. Multivariate Data Analysis: A Global Perspective, 5(6), 629-686.

Han, S. H. \& Park, H, J. (2018). The effects of franchise CEO's innovation and CSR passion, and customer orientation on perceived service qality, customer affection, and commitment. Korean Journal of Franchise Management, 9(2), 19-29.

Heskett, J. L., Jones, T. O., Loveman, G. W., Sasser, W. E., \& Schlesinger, L. A. (1994). Putting the service-profit chain to work. Harvard Business Review, 72(2), 164-174.

Hirschman, E. C., \& Holbrook, M. B. (1982). Hedonic consumption: Emerging concepts, methods and propositions. Journal of Marketing, 46(3), 92-101.

Holbrook, M. B. (1994). The nature of customer value: An axiology of services in the consumption experience. Service Quality, 21(1), 21-71.

Holbrook, M. B. (1999). Consumer value. A framework for analysis and research. Routledge: London, UK.

Holbrook, M. B., \& Hirschman, E. C. (1982). The experiential aspects of consumption: Consumer fantasies, feelings, and fun. Journal of Consumer Research, 9(2), 132-140.

Homburg, C., Müller, M., \& Klarmann, M. (2011). When does salespeople's customer orientation lead to customer loyalty? The differential effects of relational and functional customer orientation. Journal of the Academy of Marketing Science, 39(6), 795-812.

Iversen, A. C., \& Kraft, P. (2006). Does socio-economic status and health consciousness influence how women respond to health related messages in media?. Health Education Research 21(5), 601-610.

Jani, D., \& Han, H. (2014). Personality, satisfaction, image, ambience, and loyalty: Testing their relationships in the hotel industry. International Journal of Hospitality Management, 37, $11-20$.

Jensen, Ø., \& Hansen, K. V. (2007). Consumer values among restaurant customers. International Journal of Hospitality Management, 26(3), 603-622.

Jeong, E., \& Jang, S. S. (2015). Healthy menu promotions: A match between dining value and temporal distance. International Journal of Hospitality Management, 45, 1-13.

Julian, C. C., \& Ramaseshan, B. (1994). The role of customercontact personnel in the marketing of a retail bank' s services. International Journal of Retail \& Distribution Management, 22(5), 29-34.

Kim, J. G., \& Lee, Y. J. (2012). Influence of Japanese restaurants lohas image factors on customers menu selection and satisfaction. Culinary Science \& Hospitality Research, 18(4), 166-182.

Kraft, F. B., \& Goodell, P. W. (1993). Identifying the health conscious consumer. Marketing Health Services, 13(3), 18-25.

Lee, C. K., Yoon, Y. S., \& Lee, S. K. (2007). Investigating the relationships among perceived value, satisfaction, and recommendations: The case of the Korean DMZ. Tourism Management, 28(1), 204-214.

Lee, J. J., \& Lee, Y. J. (2016). The structural relationship between LOHAS image, well-being menu, emotional response, satisfaction and loyalty of hotel restaurants. Culinary Science \& Hospitality Research, 22(5), 295-312.

Lee, S. A., \& Jeong, M. (2012). Effects of e-servicescape on consumers' flow experiences. Journal of Hospitality and Tourism Technology, 3(1), 47-59.

Lee, Y.-K., Kim, S., Lee, C. K., \& Kim, S. H. (2014). The impact of a mega event on visitors' attitude toward hosting destination: Using trust transfer theory. Journal of Travel \& Tourism Marketing, 31(4), 507-521.

Lee, S.-H., Lee, Y.-K., \& Lee, J.-G. (2019). Effects of service value on attitude and loyalty in food-service franchise. Korean Journal of Franchise Management, 10(3), 13-23.

Lee, S.-H., Ah, S.-M., \& Lee, Y.-J. (2019). Effects of online food service franchise experiences on satisfaction and revisit intention. Korean Journal of Franchise Management, 10(2), 59-70. Liaw, Y. J., Chi, N. W., \& Chuang, A. (2010). Examining the mechanisms linking transformational leadership, employee customer orientation, and service performance: The mediating roles of perceived supervisor and coworker support. Journal of Business and Psychology, 25(3), 477-492.

Lytle, R. S., Hom, P. W., \& Mokwa, M. P. (1998). SERV*OR: A managerial measure of organizational service-orientation. Journal of Retailing, 74(4), 455-489.

Mathwick, C., Malhotra, N. K., \& Rigdon, E. (2002). The effect of dynamic retail experiences on experiential perceptions of value: An Internet and catalog comparison. Journal of Retailing, 78(1), 51-60.

Mehrabian, A., \& Russell, J. A. (1974). An approach to environmental psychology. MIT Press: Washington.

Moorman, C., \& Matulich, E. (1993). A model of consumers' preventive health behaviors: The role of health motivation and health ability. Journal of Consumer Research, 20(2), 208-228.

Nunnally, J. C. (1978). Psychometric theory. (2nd ed.). New York: McGraw-Hill. 
O'curry, S., \& Strahilevitz, M. (2001). Probability and mode of acquisition effects on choices between hedonic and utilitarian options. Marketing Letters, 12(1), 37-49.

Overby, J. W., \& Lee, E. J. (2006). The effects of utilitarian and hedonic online shopping value on consumer preference and intentions. Journal of Business Research, 59(10-11), 11601166.

Palmgreen, P., Wenner, L. A., \& Rosengren, K. E. (1985). Uses and gratifications research: The past ten years. In K. E. Rosengren, L. A. Wenner, \& P. Palmgreen (Eds.), Media gratifications research: Current perspectives(pp. 11-37). Beverly Hills, CA: Sage.

Reimer, A., \& Kuehn, R. (2005). The impact of servicescape on quality perception. European Journal of Marketing, 39(8), 785-808.

Robson, S. K. (1999). Turning the tables: The psychology of design for high-volume restaurants. Cornell Hotel and Restaurant Administration Quarterly, 40(3), 56-63.

Roy, R., \& Ng, S. (2012). Regulatory focus and preference reversal between hedonic and utilitarian consumption. Journal of Consumer Behaviour, 11(1), 81-88.

Rozin, P., Fischler, C., Imada, S., Sarubin, A., \& Wrzesniewski, A (1999). Attitudes to food and the role of food in life in the USA, Japan, Flemish Belgium and France: Possible implications for the diet-health debate. Appetite, 33(2), 163180.

Ryu, K., Han, H., \& Jang, S. S. (2010). Relationships among hedonic and utilitarian values, satisfaction and behavioral intentions in the fast-casual restaurant industry. International Journal of Contemporary Hospitality Management, 22(3), 416-432.

Ryu, K., Lee, H. R., \& Kim, W. G. (2012). The influence of the quality of the physical environment, food, and service on restaurant image, customer perceived value, customer satisfaction, and behavioral intentions. International Journal of Contemporary Hospitality Management, 24(2), 200-223.

Sanchez, J., Callarisa, L., Rodriguez, R. M., \& Moliner, M. A. (2006). Perceived value of the purchase of a tourism product. Tourism Management, 27(3), 394-409.

Schifferstein, H. N., \& Ophuis, P. A. O. (1998). Health-related determinants of organic food consumption in the Netherlands. Food quality and Preference, 9(3), 119-133.

Shang, R. A., Chen, Y. C., \& Shen, L. (2005). Extrinsic versus intrinsic motivations for consumers to shop on-line. Information \& Management, 42(3), 401-413.

Shieh, K. F., \& Cheng, M. S. (2007). An empirical study of experiential value and lifestyles and their effects on satisfaction in adolescents: An example using online gaming. Adolescence, 42, 199-215.

Sulek, J. M., \& Hensley, R. L. (2004). The relative importance of food, atmosphere, and fairness of wait: The case of a fullservice restaurant. Cornell Hotel and Restaurant Administration Quarterly, 45(3), 235-247.

Voss, K. E., Spangenberg, E. R., \& Grohmann, B. (2003). Measuring the hedonic and utilitarian dimensions of consumer attitude. Journal of Marketing Research, 40(3), 310-320.

Wandel, M., \& Bugge, A. (1997). Environmental concern in consumer evaluation of food quality. Food Quality and Preference, 8(1), 19-26.

Yoo, J., \& Park, M. (2016). The effects of e-mass customization on consumer perceived value, satisfaction, and loyalty toward luxury brands. Journal of Business Research, 69(12), 57755784.

Zeithaml, V. A. (1988). Consumer perceptions of price, quality, and value: A means-end model and synthesis of evidence. Journal of Marketing, 52(3), 2-22.

Zeithaml, V. A., Berry, L. L., \& Parasuraman, A. (1996). The behavioral consequences of service quality. Journal of Marketing, 60(2), 31-46. 